\title{
Progress in the science of corrosion inhibitors ${ }^{1}$
}

\author{
Yu. I. Kuznetsov \\ A. N. Frumkin Institute of Physical Chemistry and Electrochemistry, Russian Academy \\ of Sciences, Leninskii pr. 31, Moscow, 119071 Russian Federation \\ E-mail: kuznetsov@ipc.rssi.ru
}

\begin{abstract}
The physicochemical features of corrosion inhibition of metals (alloys) strongly depend on the composition of the corrosive environment, its $\mathrm{pH}$, temperature $t$, hydrodynamic conditions, the chemical nature of the metal to be protected, and the state of its surface, the presence of oxides, dirt, or corrosion products on it. This "multifactor" nature of corrosion seriously complicates the theoretical choice of an efficient corrosion inhibitor (CI), often requiring careful experimental studies and creating unjustified skepticism about the fundamental character of the physical chemistry area related to the study and development of CIs. Meanwhile, this skepticism can be proved wrong by the progress made over the past quarter century in various subareas.
\end{abstract}

Key words: corrosion inhibitors, adsorption, metal passivation, volatile corrosion inhibitors, migrating inhibitors, local depassivation of metals, protecting coatings.

Received: November 14, 2014.

doi: 10.17675/2305-6894-2015-4-1-015-034

\section{Adsorption of corrosion inhibitors on metals and passivation}

Adsorption on a protected surface is the first event that often determines CI efficiency. Difficulties of its measurement in situ are caused by dissolution and/or oxidation of the metal substrate with time. The uncertainty in separating the effects of adsorption and changes of the state of the metal surface often does not permit to unambiguously interpret the results obtained, for example, by electrochemical impedance spectroscopy (EIS) or using radioactive tracers.

In his first "Inhibitors of corrosion of metals in neutral media" (1953), I.L. Rozenfel'd considered only inorganic CIs. He remained interested in these inhibitors throughout his whole life, so it is not surprising that in his latest book "Corrosion Inhibitors" (1977) he reexamined the interaction of some inorganic CIs, primarily chromate, with the metal at a more modern level, including a quantum-chemical approach. However, studies on the

\footnotetext{
${ }^{1}$ This article is based on the plenary lecture delivered by the author at the International Conference "Corrosion inhibitors and scaling. I.L. Rozenfeld Memorial", Moscow, October 14-17, 2014. The study was supported by the Russian Foundation for Basic Research (Grant no. 13-03-00188 "Surface modification of copper, nickel and zinc by nanolayers of organic corrosion inhibitors and kinetics of their formation").
} 
adsorption of organic compounds as volatile corrosion inhibitors (VCIs) received considerable attention in his laboratory.

Intense studies of CI adsorption on metals from neutral aqueous solutions started in the mid-1980s. They became possible due to the development of ellipsometry method for estimating the adsorption on a number of metals ( $\mathrm{Fe}, \mathrm{Cu}, \mathrm{Zn}, \mathrm{Ni}, \mathrm{Al}$ ) from an aqueous solution at a controlled electrode potential. Even in our earliest works [1] on the adsorption of sodium phenylanthranilate, $\mathrm{NaOOCC}_{6} \mathrm{H}_{4} \mathrm{NHC}_{6} \mathrm{H}_{5}(\mathrm{SPhA})$, from borate buffer ( $\mathrm{pH}$ 7.4), the specific features of $\mathrm{CI}$ interaction with reduced and oxidized surface of pure Fe were identified. Despite the low free energy of CI adsorption, $\left(-\Delta G_{\mathrm{ad}}^{0}\right)<20 \mathrm{~kJ} / \mathrm{mol}$, it has been proved that its adsorption can be partially irreversible and can passivate the metal even in the absence of iron oxides. Supplementing these studies with results of studying the composition and structure of CI surface layers by ex situ XPS, polarization measurements and corrosion tests increased our knowledge of the mechanism of CI action and allowed us to scientifically substantiate the development of new methods to increase the CI efficiency.

One of these methods involves changing the CI chemical structure by introduction of a substituent $(\mathrm{R})$ in its molecule. The chemical structure is an important factor in choosing an already known CI or development of new CIs for specific conditions. Determination of the quantitative dependence of the efficiency of CIs on its parameters was a fundamental challenge that researchers faced, regardless of whether they studied active metal dissolution, passivation, or localized corrosion. Passivation of metals remains a central problem to be solved by the corrosion science. The use of CIs for this purpose played a major role not only in the application of classical oxidant-type CIs (chromates, nitrites, organic nitro compounds, etc.) but also in the adsorptive, often "non-oxide" passivation that we discovered as early as in the mid-1970s. Over the past decades the range of efficient organic passivating CIs was expanded significantly, allowing environmentally hazardous oxidants to be replaced with these compounds in many technological formulations and methods of metals protection.

In early 1980s, we have shown using the linear free energy relationship (LFER) principle [2] that the protective effect of SPhA and its derivatives can be described for different metals using the $\sigma$-constants of substituents $\mathrm{R}$ [3]. It turns out that sodium fluphenaminate, $\mathrm{NaOOCC}_{6} \mathrm{H}_{4} \mathrm{NHC}_{6} \mathrm{H}_{4} \mathrm{CF}_{3}$ (SFA) containing $\mathrm{R}=\mathrm{CF}_{3}$ at the phenyl ring, is the most efficient among them [2]. ${ }^{2}$ Later [5] it was found that the efficiency of these CIs both in passivation and in stabilization of the passive state of iron in borate-chloride solution was in good agreement with the free adsorption energy $\left(-\Delta G_{\mathrm{a}}^{0}\right)$ calculated from the adsorption isotherms measured by ellipsometric method and presented in Figure 1. The high $\left(-\Delta G_{\mathrm{a}}^{0}\right)$ values for substituted SPhA that are significantly higher than that of SPhA itself suggest that these compounds are chemisorbed on iron, which is especially noticeable

\footnotetext{
${ }^{2}$ Application of the LFER principle in the inhibition of corrosion of metals in neutral and weakly alkaline solutions was carried out by us in 1970-1980 and discussed in detail with examples of studies on various classes of organic compounds in a monograph [4].
} 
on an oxide-free electrode surface. Thus, the $\left(-\Delta G_{\mathrm{a}}^{0}\right)$ values for SFA adsorption on reduced $(56.4 \mathrm{~kJ} / \mathrm{mol})$ and oxidized $(49.6 \mathrm{~kJ} / \mathrm{mol})$ pure iron are 3.6 and 2.9 times higher, respectively, than those in the case of SPhA. The results of a study on SFA desorption support the fact of CI chemisorption.
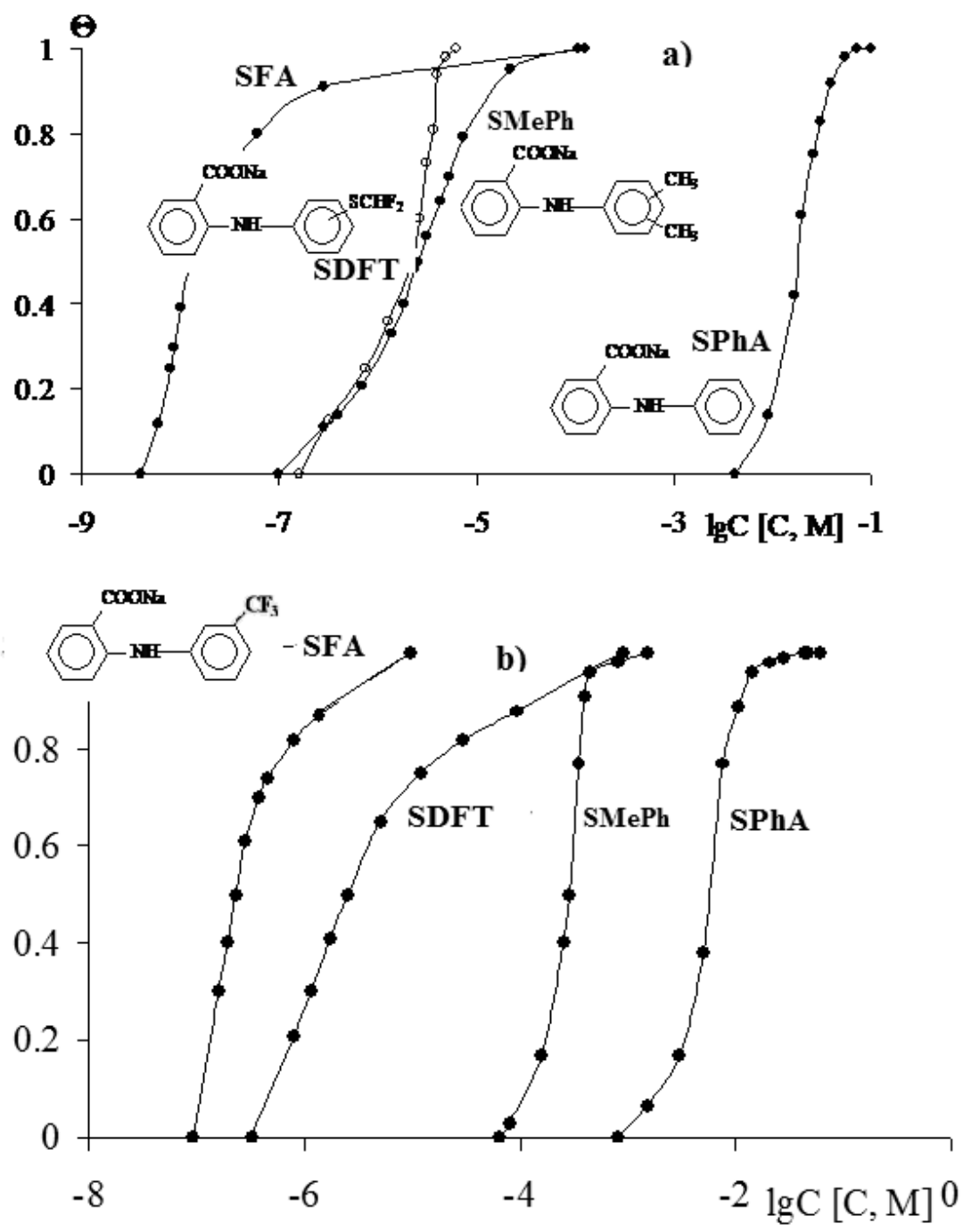

Figure 1. Dependence of the coverage degree $(\Theta)$ of reduced $(a, E=-0.65 \mathrm{~V})$ and oxidized $(b, E=0.20 \mathrm{~V})$ zone melted iron on the concentration of inhibitors in borate buffer, $\mathrm{pH} 7.4$, upon adsorption.

The irreversibility of SFA adsorption allowed us to study by an ex situ method, namely XPS, the monolayers formed by its anions in aqueous solution on mild steel [6]. In these studies, L.P. Kazansky simulated an adsorption film of SFA by dividing it into planar layers containing specific atoms of vertically oriented SFA molecules (Figure 2a). Taking into account the size of the SFA anion for calculating the relative intensities of the respective peaks as a function of angle $\alpha$, he chose the following layer thicknesses: $0.3 \mathrm{~nm}\left(\mathrm{CF}_{3}\right), 0.5$ $\mathrm{nm}\left(\mathrm{C}_{6} \mathrm{H}_{4}\right), 0.11 \mathrm{~nm}(\mathrm{NH})$, and $0.5 \mathrm{~nm}\left(\mathrm{C}_{6} \mathrm{H}_{4} \mathrm{COO}^{-}\right)$. For such a layered model, Figure $2 \mathrm{~b}$ shows the angular dependence of the ratio of the relative intensities of $\mathrm{Fe}(\mathrm{ox}) / \mathrm{Fe}(\mathrm{m}), \mathrm{F} / \mathrm{N}$ 
and $\mathrm{F} / \mathrm{C}$ at different angles $\alpha$ normalized to the same relations determined at angle $\alpha=0^{\circ}$. It is known [7] that the surface roughness can make a significant contribution to the calculations of the layer under study and interpretation of the XPS data can be quite complicated. Despite this, calculations of the thickness of the adsorption layer of SFA and a study of the angular resolution of the spectra clearly confirmed that this CI formed a monomolecular layer in which the SFA anions are oriented vertically or slightly obliquely with respect to the surface. They interact with the iron surface through the oxygen of the carboxy groups and the upper film layer is formed by $\mathrm{CF}_{3}$ groups. One can conclude that the molecules are stacked in upright position forming, presumably, a self-assembled molecular layer. In this layer the adjacent molecules hold each other by $\pi-\pi$ interactions between the phenyl rings favoring strong adsorption on the steel surface.
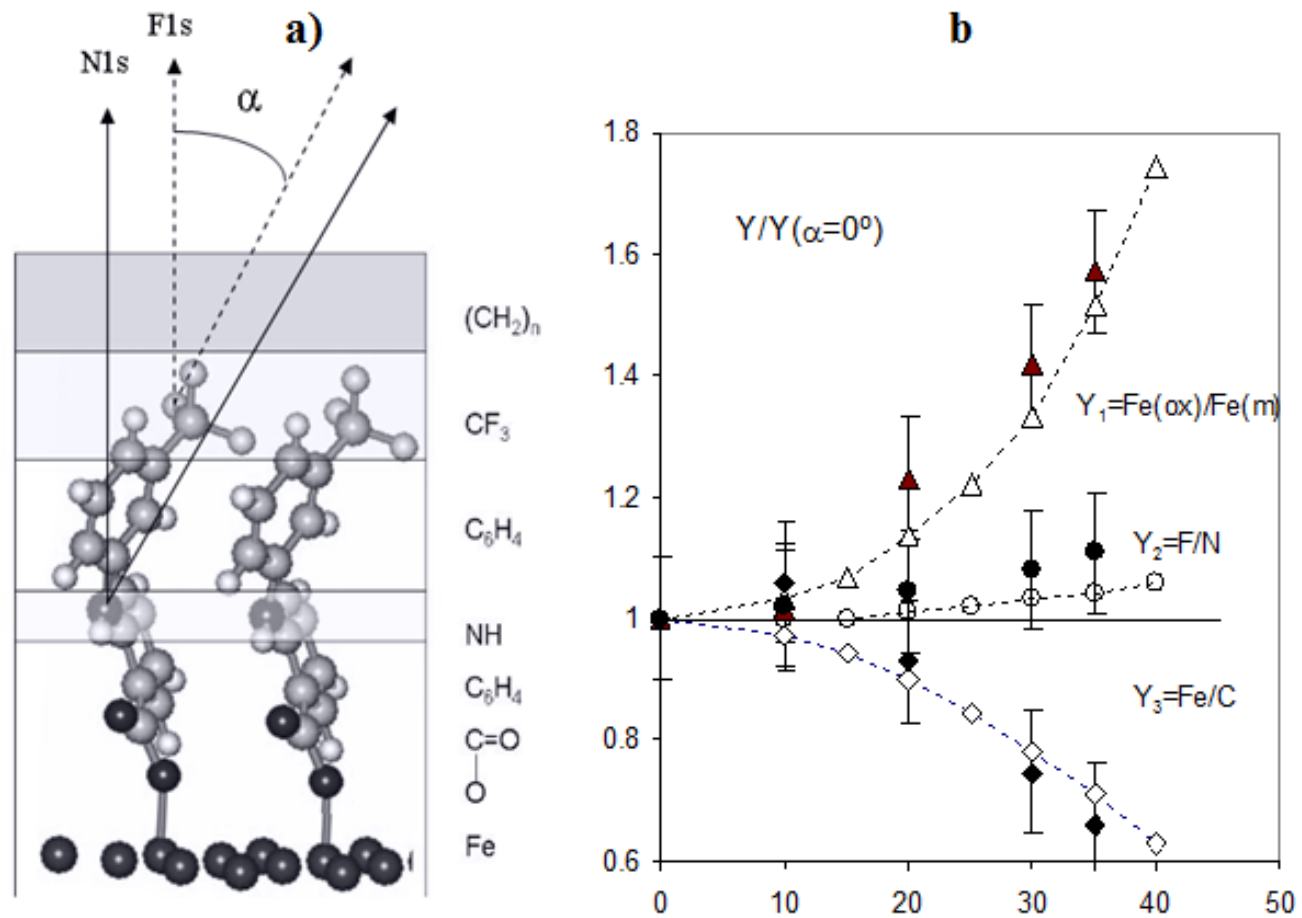

Figure 2. $a$, estimated orientation of SFA molecules on steel surface; $b$, angular dependence of the ratio of relative intensities $\mathrm{Fe}_{\mathrm{ox}} / \mathrm{Fe}_{\mathrm{m}}, \mathrm{F} / \mathrm{N}$ and $\mathrm{Fe} / \mathrm{C}$ at different angles $\alpha$, normalized to the same ratio determined at $\alpha=0^{\circ}$. Here the black points were taken from the experiment and the dashed lines show calculated values.

Adsorption is important not only in the protective effect of adsorption type CIs. It is known that, in addition to adsorption interaction with the metal, many CIs of complexation type are capable of forming multilayer films comprising a polymeric compound formed by cations of the metal being protected [4, 8-12]. These CIs often include azoles, for example aminotriazoles $[9,13,14]$.

Adsorption of aminotriazoles can occurs at very low inhibitor concentrations, $C_{\text {in }}$, as evidenced by a decrease in the ellipsometric angle $\Delta$ with addition to the solution of even fractions of $\mu \mathrm{mol} / 1$ of a CI (Figure 3). As $C_{\text {in }}$ increases, saturation of copper surface by 
adsorbed aminotriazole is reached, which is manifested as a plateau on the plot of $\delta \Delta=$ $\Delta_{\text {in }}-\Delta_{0}$ versus $\lg C_{\text {in }}$. It can be explained by formation of a conditional monolayer of the adsorbate. However, a further increase in $C_{\text {in }}$ makes the changes in ellipsometric angle $\Delta$ unsteady: it changes over time, at least for several hours. It is possible that copper cations are accumulated slowly in solution and form complex compounds with CI that are adsorbed to form subsequent layers. It is possible that polymerization occurs in the protective film as well. If we limit ourselves to the region of low $C_{\mathrm{in}}$, in which a conventional monolayer is formed, the adsorption isotherm of the CI can be adequately described by the Temkin equation:

$$
\Theta=(1 / f) \ln \left[B_{\max } C_{\text {in }}\right],
$$

where $B=\left[\exp \left(-\Delta G_{\mathrm{a}}^{0} / R T\right)\right] / 55.5$ is the adsorption equilibrium constant and $f$ is the factor of energy inhomogeneity of the surface.

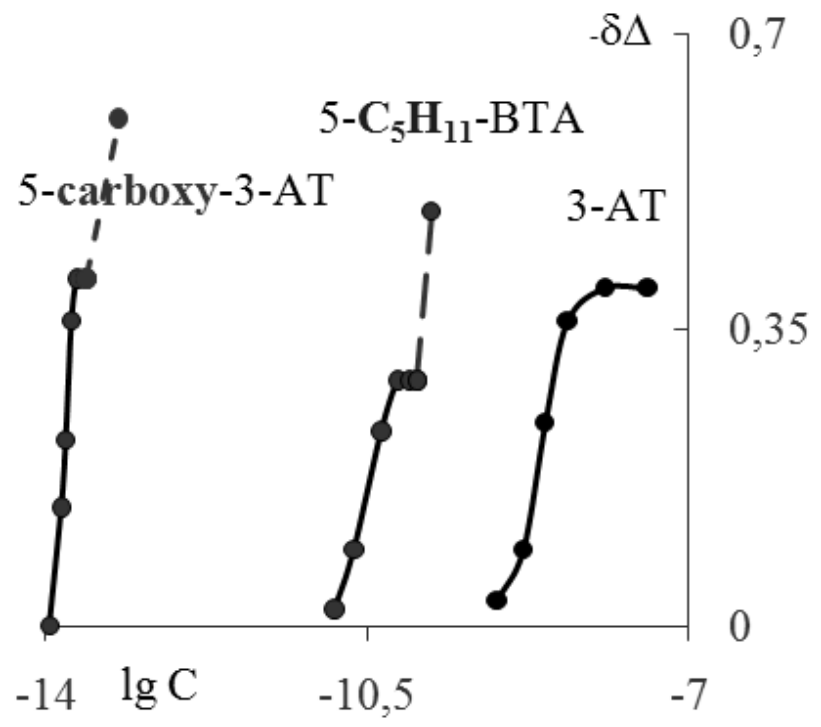

Figure 3. Dependence of ellipsometric angle variation, $\delta \Delta=\Delta_{\text {in }}-\Delta_{\text {bkgr }}$, on copper in borate buffer solution at $\mathrm{pH} 7.4$ on the concentration of triazoles indicated near the respective curves.

Given that a passivating film with such a complex composition is formed, it is difficult to determine the contribution of CI absorption to the efficiency of metal protection. However, this can be done using the LFER principle and a combination of adsorption and corrosion-electrochemical measurements. As early as in 1980, we identified a linear dependence of the logarithm of protective concentrations of substituted benzimidazoles [4, 15], and later of thiazoles [16], on copper and zinc in a phosphate solution at $\mathrm{pH} 11.7$, on induction constants $\left(\sigma_{\mathrm{I}}\right)$ of $\mathrm{R}$ in the inhibitor molecules. ${ }^{3}$ Protection of copper becomes more efficient when $\mathrm{R}$ is an electron acceptor $\left(\sigma_{\mathrm{I}}>0\right)$, whereas protection of zinc is favored by electron-donor R's $\left(\sigma_{\mathrm{I}}<0\right)$. To explain the opposite effect of $\mathrm{R}$, we assumed that it is due to

\footnotetext{
${ }^{3}$ At $C_{\text {in }}=$ const, a similar dependence was established for yet another criterion of CI efficiency, namely, the inhibition coefficient calculated from the rates of anodic dissolution of the metal, $\gamma_{\mathrm{an}}=i_{\mathrm{bckgr}} / i_{\text {in }}$.
} 
differences in the nature of the chemical bond between a CI and the cations of the metal being protected in the complex compounds formed. Introduction of electron-accepting $\mathrm{R}$ reduces the electron density at the reaction center, thus weakening the $\sigma$-bond in complex compounds, but enhances dative $\pi$-bonds formed by partial transfer of free $d$-electrons from the complex-former to the vacant orbitals of the ligand [17]. This is particularly important in protection of copper that occurs through the formation of sparingly soluble $\mathrm{Cu}(\mathrm{I})$ complexes with a ligand. In $\sigma$-bonds, a ligand serves as an electron donor and metal as an acceptor, therefore introduction of electron-donating R's in the ligand molecule increases the stability of the complexes of zinc and protection of the latter.

Extensive experimental data allowed us to suggest that the regularities that we obtained also hold for solutions of other heterocyclic CIs. Indeed, in a borate-chloride solution with $\mathrm{pH} 7.4$, the minimal $C_{\text {in }}$ required for spontaneous passivation of copper is the smaller, the higher the value of $\sigma_{\mathrm{I}}$, i.e., the electron-accepting properties of $\mathrm{R}$ in the molecules of 5-substituted 3-amino-1,2,4-triazoles (Figure 4a). It is essential that a similar dependence is observed for the $\left(-\Delta G_{\mathrm{a}}^{0}\right)$ value of aminotriazoles measured at their $C_{\mathrm{in}}$, where the electrode surface is covered by less than a monolayer of CI molecules. Apparently, it is CI chemisorption that determines its efficiency, while the modified layers formed on its surface play just a secondary role.
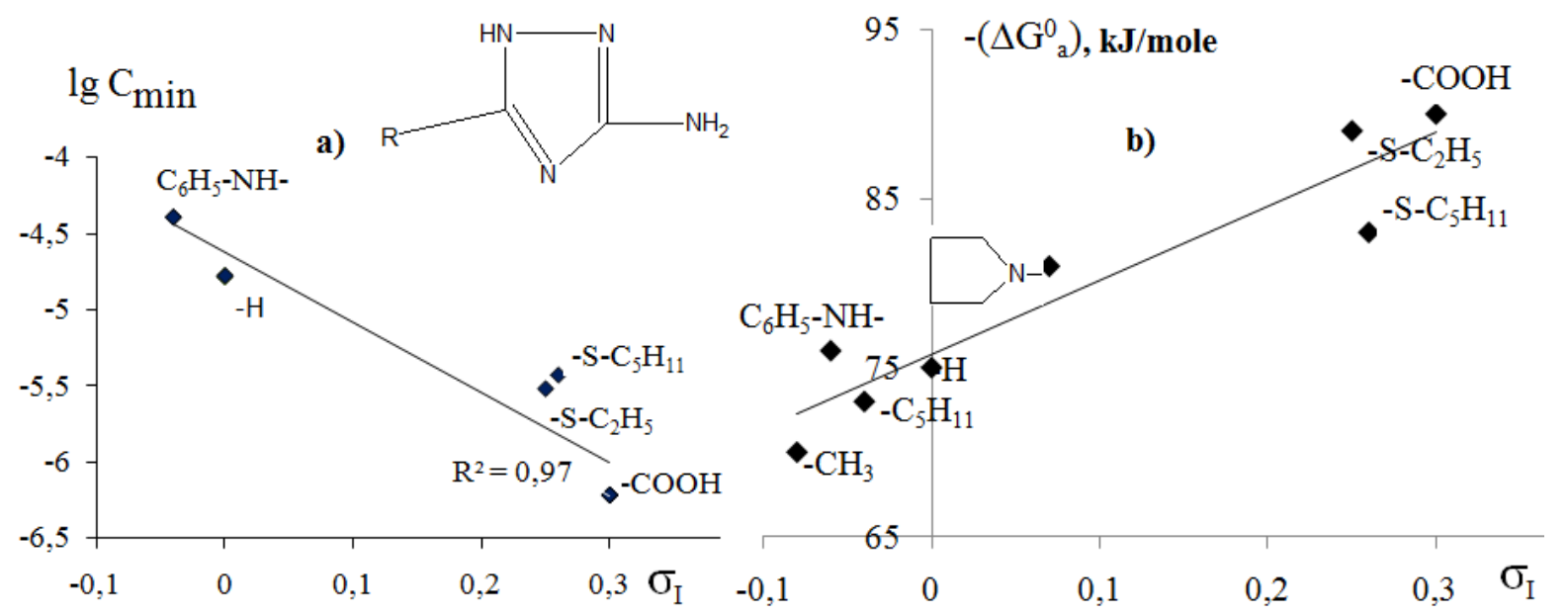

Figure 4. Dependence of: $a$, the free energy of adsorption for triazoles on $\sigma_{\mathrm{I}}$ constants of substituents $\mathrm{R}$ on copper in borate buffer with $\mathrm{pH} 7.40$, and $b$, the logarithm of the minimum concentration that provides spontaneous passivation of copper in the same buffer containing $10 \mathrm{mmol} / \mathrm{l} \mathrm{NaCl}$ on the $\sigma_{\mathrm{I}}$ constants of $\mathrm{R}$.

However, there are cases where besides CI chemisorption that allows it (or its fragment) to hold firmly to the metal surface, an important role is played by deep chemical transformations of adsorbate particles that lead to structuring of the protective film and make it more resistant to a corrosive environment. The CIs of this kind include some acetylenic alcohols that are long known for their efficiency in acid solutions even at $t>$ $100^{\circ} \mathrm{C}$ [18-21]. Unfortunately, they are very toxic and a search for their replacement is 
very relevant. Some authors believe that unsaturated aldehydes that are highly efficient CIs can be alternatives to acetylene derivatives. Their efficiency is also largely determined by their ability to chemical reactions on the metal surface being protected, as recently confirmed by Ya.G. Avdeev et al. [22] by means of chromato-mass spectrometric analysis.

In neutral media, trialkoxysilanes deserve attention in this regard. In the presence of water, the hydrolyzable alkoxy group tends to form a reactive silanol group ( $\mathrm{SiOH})$, which reacts with a hydroxyl group on the metal surface to form siloxane $(\mathrm{Si}-\mathrm{O}-\mathrm{Si})$ and metalsiloxane (Me-O-Si) covalent bonds [23]. The hydrolysis reaction proceeds spontaneously, without catalysts, but acids or bases accelerate the hydrolysis of silanes. Of the silanes that we investigated, the highest passivating ability towards carbon steel belongs to [3-(2aminoethylamino)propyl] trimethoxysilane $\mathrm{H}_{2} \mathrm{NC}_{2} \mathrm{H}_{4} \mathrm{NHC}_{3} \mathrm{H}_{6} \mathrm{Si}\left(\mathrm{OCH}_{3}\right)_{3}$ (AEAPTS) [24]. Spontaneous passivation of a steel electrode was observed upon addition of $0.5 \mathrm{mmol} / 1$ AEAPTS to neutral borate buffer, or $0.25 \mathrm{mmol} / 1$ if exposure time is increased to $60 \mathrm{~min}$ (Table 1). Such a low protective $C_{\text {in }}$ puts AEAPTS, although it is not an anion, on a par with very efficient water-soluble non-oxidizing passivators for mild steel.

Comparison of $\left(-\Delta G_{\mathrm{a}}^{0}\right)$ values determined from $\mathrm{CI}$ isotherms, i.e., obtained under conditions of equilibrium adsorption with electrochemical characteristics drawn from kinetic studies, allows one to evaluate the efficiency of the passivating action of CI. As one can see from the results shown in Table 1, CI having a greater $\left(-\Delta G_{\mathrm{a}}^{0}\right)$ value usually passivated steel at a smaller $C_{\text {in }}$. This conclusion is valid for organic anions within the same class of organic compounds. For example, the passivating effect of sodium carboxylates increases in the series: SPhA - SFA - sodium phenylundecanate (SPhU) sodium oleylsarcosinate (SOLS). The same sequence is observed for the hydrophobicity of their anions, which can be calculated from the equation [25]:

$$
\log D=\log P-\log \left[1+10^{\mathrm{pH}-\mathrm{p} K_{\mathrm{a}}}\right],
$$

where $P$ is the distribution coefficient of a compound in question in a system of two immiscible liquids, octanol-water, and the second term of equation corrects for its dissociation, in the case under discussion, of the organic acid. In this series, the highest value of $\left(-\Delta G_{\mathrm{a}}^{0}\right)$ is observed for SOLS, which also shows the best passivating properties.

Similarly, increasing the hydrophobicity of the anions affects the adsorption and passivation properties of not only $\mathrm{NH}$-acids (from BTA to Cl-BTA) but also salts of organophosphorus acids. Though SDOPh is inferior to SOLS in this respect, it still remains an excellent passivator for steel, especially upon long electrode exposures in a passivating solution. SOPh has a significant $\left(-\Delta G_{\mathrm{a}}^{0}\right)$, but its adsorption is very slow due to the hydrophilicity of the double-charged anion. Although the charge of the surface is unknown for us, we can assume that it is negative, and hence, adsorption of such an anion thereon is more difficult. Prolonged exposure of the electrode to a solution or an increase in $t$ to $60^{\circ} \mathrm{C}$ reduces the passivating $C_{\mathrm{in}}$ of $\mathrm{SOPh}$ by more than an order (to 0.3 and $0.1 \mathrm{mmol} / \mathrm{l}$, respectively [26]). 
Table 1. Passivating effect of corrosion inhibitors determined from polarization curves on steel after electrode exposure in borate buffer containing CIs and $10 \mathrm{mM} \mathrm{NaCl}$, free adsorption energies of CIs on mild steel in borate buffer ( $\mathrm{pH} 7.4), \mathrm{p} K_{\mathrm{a}}$ and $\lg D$ of CIs.

\begin{tabular}{|c|c|c|c|c|c|}
\hline \multirow[b]{2}{*}{ Corrosion inhibitor } & \multirow{2}{*}{$\begin{array}{c}\text { Electrode } \\
\text { exposure time } \\
\text { in the solution }\end{array}$} & \multicolumn{2}{|c|}{$\begin{array}{l}\text { Protective effect and }-\Delta G_{\mathrm{a}}^{0} \\
\text { for adsorption on mild steel }\end{array}$} & \multirow[b]{2}{*}{$\mathbf{p} K_{\mathbf{a}}$} & \multirow[b]{2}{*}{$\lg \mathrm{D}$} \\
\hline & & $\begin{array}{c}C_{\text {in }} \text { for steel } \\
\text { passivation, } \\
\text { mmol/l }\end{array}$ & $\begin{array}{l}E=-0.65 \mathrm{~V} ;-\Delta G_{\mathrm{a}}^{0} \text { in } \\
\mathrm{kJ} / \mathrm{mol} \text {; Isotherm type }\end{array}$ & & \\
\hline $\mathrm{SPhA}$ & 15 & 8.00 & 18.3; Frumkin & 3.43 & 1.40 \\
\hline SFA & as above & 3.80 & 23.0; as above & 3.67 & 2.69 \\
\hline \multirow{2}{*}{ 1,2,3-Benzotriazole, BTA } & as above & 4.00 & \multirow{2}{*}{ 29.0; as above } & \multirow{2}{*}{8.38} & \multirow{2}{*}{1.32} \\
\hline & 60 & 1.00 & & & \\
\hline \multirow{2}{*}{ 5-Chloro-BTA } & 15 & 1.50 & \multirow{2}{*}{ 45.6; as above } & \multirow{2}{*}{5.46} & \multirow{2}{*}{1.30} \\
\hline & 60 & 0.75 & & & \\
\hline \multirow{2}{*}{$\begin{array}{c}\text { Sodium phenylundecanate, } \\
\text { SPhU }\end{array}$} & 15 & 0.95 & \multirow{2}{*}{34.2 ; as above } & \multirow{2}{*}{4.78} & \multirow{2}{*}{3.68} \\
\hline & 60 & 0.50 & & & \\
\hline \multirow{2}{*}{$\begin{array}{l}\text { Sodium octylphosphonate, } \\
\qquad \mathrm{C}_{8} \mathrm{H}_{17} \mathrm{PO}_{3} \mathrm{Na}_{2}\end{array}$} & 15 & $>4.0$ & \multirow{2}{*}{ 36.3; Temkin } & \multirow{2}{*}{$\begin{array}{l}2.4 \\
7.8\end{array}$} & \multirow{2}{*}{1.79} \\
\hline & 120 & 0.30 & & & \\
\hline \multirow{2}{*}{$\begin{array}{l}\text { Sodium dioctylphosphate, } \\
\text { SDOPh }\end{array}$} & as above & 0.40 & \multirow{2}{*}{37.8 ; as above } & \multirow{2}{*}{1.51} & \multirow{2}{*}{2.96} \\
\hline & 90 & 0.05 & & & \\
\hline \multirow{2}{*}{ AEAPTS } & 15 & 0.50 & \multirow{2}{*}{ 45.1; as above } & \multirow{2}{*}{-} & \multirow{2}{*}{-} \\
\hline & 60 & 0.25 & & & \\
\hline \multirow{2}{*}{$\begin{array}{c}\text { Sodium oleylsarcosinate, } \\
\text { SOLS }\end{array}$} & 15 & 0.05 & \multirow{2}{*}{ 55.8; as above } & \multirow{2}{*}{3.55} & \multirow{2}{*}{4.03} \\
\hline & 60 & 0.03 & & & \\
\hline \multicolumn{6}{|c|}{ Compositions of corrosion inhibitors } \\
\hline ГГ $V$ - & 15 & 0.80 & 11 0. Гnuml & & \\
\hline IFKnAN $\angle J F$ based on SFA & 60 & 0.50 & 41.8; Frumkin & & \\
\hline CDbI & 15 & 0.20 & 12 4. Toml. & & \\
\hline SPhU+B IA & 60 & 0.05 & 42.4; Temk1n & & \\
\hline Passivating formulation & 15 & 0.04 & & & \\
\hline based on SOLS & 60 & 0.02 & & & \\
\hline
\end{tabular}

It should be noted that the above-mentioned "non-oxide" adsorption passivation was first observed in solutions of SPhA, which is characterized by the smallest $\left(-\Delta G_{\mathrm{a}}^{0}\right)$, so the significant expansion of the range of efficient organic CIs of passivator type over the past 
decades is not surprising. This allowed environmentally hazardous oxidants to be replaced in many technological formulations and methods of metal protection.

The second method of increasing the passivating properties of CIs that is based on development of mixtures in which the components enhance the protective effects of each other, also continues to expand (Table 1). For example, IFKhAN-25F developed in our laboratory based on SFA is several times more efficient and cheaper than the latter. The passivating effect of the SPhU-BTA mixture is significantly higher than those of its components $[27,28]$. Even the protective effect of SOLS, which was the best among individual organic passivators for mild steel, can be increased by using it in formulation with a less efficient but cheaper corrosion inhibitor.

Application of mixed corrosion inhibitors can not only lower their cost and facilitate the passivation of metals, but also decrease the drawbacks of inhibitors. In fact, some passivating CIs are not efficient in stabilizing the passive state of steel, i.e., impede its local depassivation by chlorides or $\mathrm{SO}_{4}^{2-}$ (BTA, AEAPTS), and vice versa, other CIs can even stimulate active dissolution of steel, but in the presence of an oxide film or a strong passivating CI they can enhance steel protection from depassivation. Table 2 shows examples of improving the protection of steel by joint use of various CIs. It can be noted that individual compounds, including SOLS, are usually inferior to formulations in stabilization of the passive state of mild steel.

Development of the third method of improving the passivation of metals started rather recently [29]. It is an attempt to improve the second method and is based on the already established fact that one mixture component can initiate adsorption of another CI. Its essence lies in the preliminary modification of the surface by any chemical compound that enhances the adsorption of the other reactant.

The modification can be performed by a chemisorbed reagent that is difficult to displace from the surface by another adsorbate, if at all possible. For example, SPhU adsorbed quite strongly on oxidized zone-melted iron with $-\Delta G_{\mathrm{a}}^{0}=33.1 \mathrm{~kJ} / \mathrm{mol}$, so a SMEPh anion whose adsorption is weaker $\left(-\Delta G_{\mathrm{a}}^{0}=27.3 \mathrm{~kJ} / \mathrm{mol}\right)$ cannot easily replace the former from the surface (Figure 5) [29]. Moreover, it was shown that the higher the degree of surface coverage with a modifier ( $\mathrm{SPhU}$ ), the easier SMEPh adsorption proceeds. If $\mathrm{SMEPh}$ adsorption occurs on iron already modified with a monolayer of SPhU, its adsorption isotherm is better described by the Temkin rather than Frumkin equation and $-\Delta G_{\mathrm{a}}^{0}$ increases to $38.4 \mathrm{~kJ} / \mathrm{mol}$. It is possible that strong attractive interaction exists between adsorbed particles of different anions. This hypothesis is supported by the fact that a third layer consisting of SPhU anions can be adsorbed on such an electrode. For this purpose, after the two-layer coating consisting of $\mathrm{SPhU}$ and $\mathrm{SMePh}$ monolayers was created, the solution was again replaced with blank buffer solution while supporting the electrode potential at $E=0.2 \mathrm{~V}$, and then $\mathrm{SPhU}$ was added to it. The isotherm obtained in this manner is accurately described by the Langmuir equation

$$
B C=\Theta /(1-\Theta)
$$


The value $-\Delta G_{\mathrm{a}}^{0}=39.2 \mathrm{~kJ} / \mathrm{mol}$ formally calculated for this case is noticeably larger than that obtained for the first layer of SPhU adsorbed on oxidized iron. It is quite unusual for adsorption films. Furthermore, one can assume that an electrode surface coated with two adsorption layers becomes energetically more homogeneous than the original oxidized surface after adsorption of the first SPhU layer.

Table 2. Protective effect of corrosion inhibitors in the local depassivation of St $3, \Delta E=E_{\mathrm{p}}^{\text {in }}-E_{\mathrm{p}}^{\mathrm{bckgr}}$, their free energies of adsorption on oxidized steel $\left(-\Delta G_{\mathrm{a}}^{0}\right)$ at $E=0.2 \mathrm{~V}$ and physicochemical characteristics.

\begin{tabular}{cccccc}
\hline Inhibitor & $\begin{array}{c}\left(-\Delta G_{\mathbf{a}}^{0}\right), \\
\mathbf{k J} / \mathbf{m o l}\end{array}$ & $\begin{array}{c}\text { Isotherm } \\
\text { type }\end{array}$ & $\begin{array}{c}\boldsymbol{\Delta} \boldsymbol{E}, \mathbf{V} \text { at } \\
\boldsymbol{C}_{\mathbf{i n}}=\mathbf{2 . 0} \mathbf{~ m m o l} / \mathbf{l}\end{array}$ & $\mathbf{p} \boldsymbol{K}_{\mathbf{a}}$ & $\mathbf{I g} \boldsymbol{D}$ \\
\hline SDOPh & 32.2 & Temkin & 0.27 & 1.51 & 2.96 \\
SOLS & 38.9 & as above & 0.20 & 3.55 & 4.03 \\
BTA & 19.2 & Frumkin & 0.02 & 8.38 & 1.32 \\
SPhU & 30.2 & as above & 0.15 & 4.78 & 3.68 \\
SPhU + BTA & 48.7 & as above & 0.28 & & \\
SMePh & 29.8 & as above & 0.15 & 4.3 & 1.09 \\
SPhU + SMePh & 41.1 & Temkin & 0.50 & & \\
5-Chloro-BTA & 37.4 & Frumkin & 0.03 & 7.70 & 2.96 \\
SFA & 21.1 & as above & 0.12 & 3.67 & 2.69 \\
SFA+ 5-cloro-BTA & 58.5 & Temkin & 0.34 & & \\
Sodium oleate, SOL & 34.0 & Frumkin & 0.16 & 4.78 & 5.48 \\
SFA + SOL & 46.5 & Temkin & 0.24 & & \\
\hline
\end{tabular}

Thus, by sequentially adsorbing organic anions on metals, we can increase their free absorption energy and hence improve the protective properties of these nano-sized adsorption layers (their total thickness does not exceed $5 \mathrm{~nm}$ ). It is significant that this method of successive adsorption is possible from very dilute solutions of individual CIs. In [28] it was shown that $\mathrm{SPhU}$ pre-adsorption on oxidized iron also promotes the adsorption of BTA at lower $C_{\text {in }}$. 


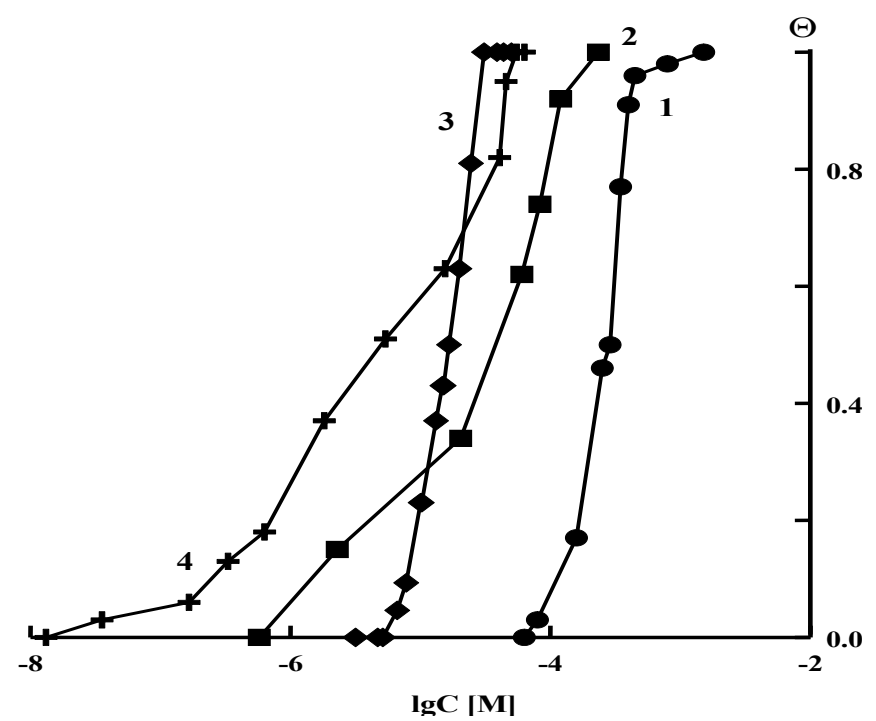

Figure 5. Adsorption isotherms of sodium salts of organic acids and their blends on oxidized iron surfaces at $E=0.2 \mathrm{~V}: \mathrm{SMEPh}$ without (1) and with preliminary adsorption of SPhU (2), $\mathrm{SPhU}$ without (3) and with preliminary formation of a two-layered SPHU + SMEPh coating (4).

However, a high surface coverage by a pre-adsorbed inhibitor does not always beneficially affect the subsequent adsorption of other CIs. We have found that the dependence of BTA adsorption on the surface coverage by SFA pre-adsorbed on an iron electrode passes through a maximum [30]. If a monolayer of SFA is preliminarily formed on a steel surface, BTA cannot be adsorbed on it at all. However, BTA adsorption is enhanced and reaches an optimum if the preliminary coverage with SFA is $\Theta=0.33-0.50$. In this case, the BTA adsorption energy reaches $52-58.7 \mathrm{~kJ} / \mathrm{mol}$ (Figure 6). It can be assumed that the attractive interactions between vertically oriented SFA anions and BTA particles are facilitated in the case of triazole adsorption on a free surface of oxidized steel due to the side interactions of their aromatic rings.

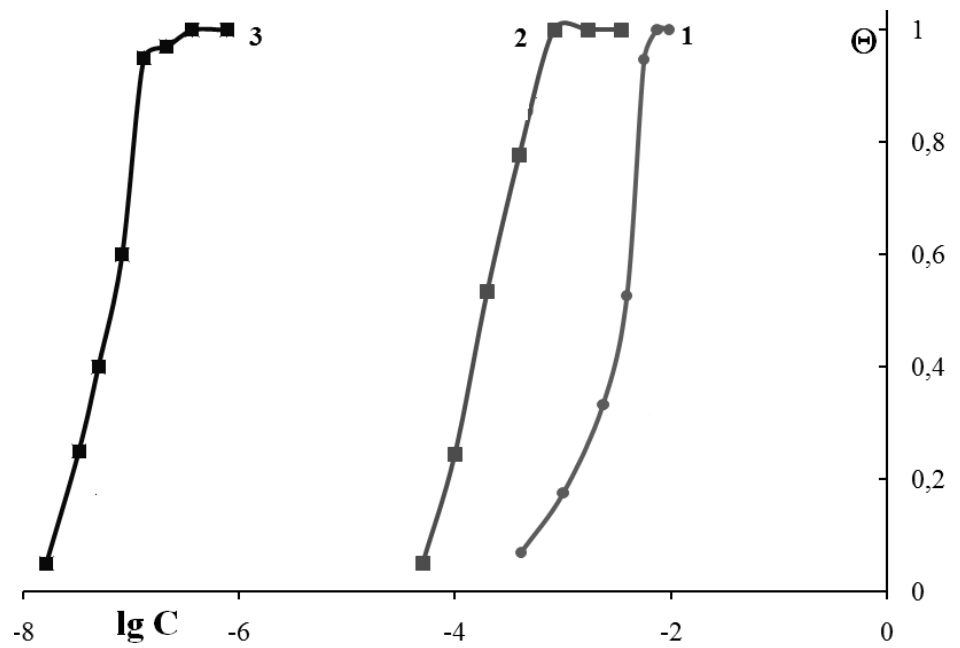

Figure 6. Variation of the degree of coverage of the concentration of inhibitors: SFA (1), BTA (2) for their adsorption on the oxidized surface of St3 $(E=0.2 \mathrm{~V})$, and layered BTA adsorption (3) on an electrode previously modified with SFA at $\Theta_{\mathrm{SFA}}=0.33$. 
Corrosion tests in a wet atmosphere with forced daily water condensation on the steel surface confirmed the conclusion regarding the dependence of the protective effects of BTA on $\Theta_{\text {SFA }}$ (Table 3). Passivation of steel by dilute solutions of BTA or SFA is inefficient. The protective effect is slightly enhanced if a blend of these CIs is used. The best result is obtained after two-stage adsorption, where initial adsorption of SFA yields $\Theta$ $=0.33$ and then the surface is treated with a BTA solution. In this case, the time before the appearance of corrosion $(\tau)$ is more than 10 days, whereas at $\Theta=0.5$, it is more than two times shorter.

The efficiency of the developed metal passivation method is shown by the results of testing ultrathin coatings prepared on steel treated in solutions of: first, zinc 1,1hydroxyethylidenediphosphonate (HEDPZn), and second, "AKN" carboxylate [31]. Under these harsh conditions, the first traces of corrosion appear only after 39 days. Of course, the mechanism of such surface modification is beyond purely adsorptive interaction, but the coating remains very thin, like in the case where silanes or their fluorinated derivatives are used in such treatment, and the protective effect can be many times greater than that of the commonly used thick anticorrosion coatings. We can expect that in the near future, this method of metal passivation with various CIs will open new opportunities to improve environmental safety and efficiency of metal protection in practice.

Table 3. Effect of the method and composition of the passivating solution on the protective properties of adsorption films with respect to mild steel $\mathrm{St} 3$ in a humid atmosphere $(100 \% \mathrm{RH})$ under conditions of daily water condensation on steel samples.

CI aqueous solution (concentration, mol/l)

\begin{tabular}{cc}
\hline SFA (1-3) & $3.8 \pm 0.3$ \\
\hline BTA (3) & $1.4 \pm 0.2$ \\
\hline SFA + BTA (3) & $5.8 \pm 0.2$ \\
\hline $\begin{array}{c}\text { First layer: SFA with } \Theta=0.10 \\
\text { Second layer: BTA (3) }\end{array}$ & $9.0 \pm 0.4$ \\
\hline $\begin{array}{c}\text { First layer: SFA with } \Theta=0.33 \\
\text { Second layer: BTA (3) }\end{array}$ & $10.4 \pm 0.3$ \\
\hline $\begin{array}{c}\text { First layer: SFA with } \Theta=0.5 \\
\text { Second layer: BTA (3) }\end{array}$ & $5.0 \pm 0.3$ \\
\hline HEDPZn (8) & $3.0 \pm 0.3$ \\
\hline Carboxylate A (8) & $2.5 \pm 0.2$ \\
\hline HEDPZn (8) + Carboxylate A & $14.0 \pm 1.0$ \\
\hline $\begin{array}{c}\text { First layer: HEDPZn (8) } \\
\text { Second layer: Carboxylate A (8) }\end{array}$ & $39.0 \pm 1.0$ \\
\hline
\end{tabular}

Time before appearance of first corrosion damage, days 


\section{Goal-oriented corrosion inhibitors}

Perhaps, volatile corrosion inhibitors (VCIs) form the most specific class of corrosion protection means. A great contribution to the theory of action and application of these inhibitors was made by I.L. Rosenfeld. Developments in this field continued in our Institute in subsequent years, and we should distinguish the following achievements:

- development of $\zeta$-constant scale of volatility of organic compounds [32], which based on the LFER-principle allows a quantitative estimation of the volatility of VCIs with good accuracy;

- discovery of the possibility of joint use of VCI together with volatile trialkoxysilanes $[33,34]$ providing reliable corrosion protection of a wide range of metals under severe conditions of periodic water condensation on the surfaces;

- partial polymerization in nanolayes containing a trialkoxysilane can significantly increase the irreversibility of adsorption and its protective aftereffect;

- development of efficient VCIs for corrosive $\mathrm{CO}_{2}-[35,36]$ and $\mathrm{H}_{2} \mathrm{~S}$-containing gases [37-41] commissioned by major oil and gas companies.

Migrating CIs (MCIs) are another specific type of corrosion inhibitors that appeared only in the 1990s [42]. Their effect is based on the ability of molecules or ions of a MCI to penetrate through the layer of the substance that shields metal, followed by its adsorption on the surface to form a protective film. They are used in the maintenance of concrete structures, although it is not difficult to predict that the area of their application would widen in the near future. It has been proved in recent years [43-45] that an efficient MCI, for example IFHAN-80, is well absorbed into concrete stone due to capillary leak, and can reach steel bars at a depth of up to $15-20 \mathrm{~cm}$ and protect them against corrosion. The rate of its consumption in this case is $0.6-1.2 \mathrm{~L} / \mathrm{m}^{2}$.

High-temperature acid corrosion inhibitors are designed to address the long-known problem of enhancing oil recovery that is achieved by acid treatment of deep wells, where $t$ can be $\geq 160^{\circ} \mathrm{C}$. Under such conditions the majority of organic CIs for strongly acidic environments lose their protective properties toward steel. Acetylenic compounds are an exception, but they are usually fire hazardous, toxic, and tend to resinify at high temperatures, thus they are not widely applied in practice. In recent years, new CIs have been developed that belong to the class of more heat-resistant heterocyclic compounds and that lack many drawbacks of acetylenic CIs [46]. They are not only heat-resistant, but also efficient $\mathrm{CIs}$ in $\mathrm{HCl}$ and $\mathrm{H}_{2} \mathrm{SO}_{4}$ solutions. In the latter case, they are thermally stable and are able to protect metals up to $200^{\circ} \mathrm{C}$. As an example, Figure 7 shows the corrosion rate and inhibition factor of IFKhAN-92 and its composition with a cheaper heterocyclic amine that is not sufficiently efficient by itself but can enhance the protection of mild steel by the mixed inhibitor [47]. It can be particularly efficient at elevated temperatures. 

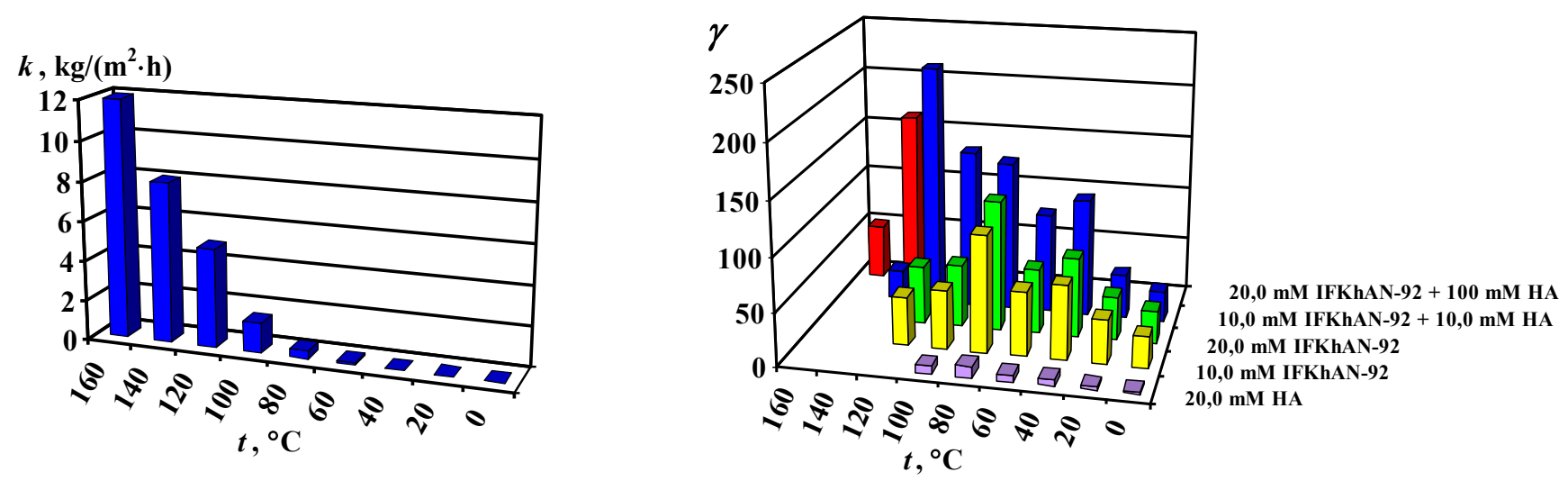

Figure 7. Corrosion rates of steel 20 in $2.0 \mathrm{M} \mathrm{HCl}$ and inhibition coefficients of steel 20 by IFKhAN-92, HA additive, and their combinations as a function of temperature.

Conversion coatings (CCs) on metals are inconceivable without the use of CIs, and the problems of replacing nitrites and chromates and reducing the energy consumption in obtaining CCs has only increased the role of inhibitors. The achievements in this field can be demonstrated using oxidation of low-carbon steels as an example. They include:

- the possibility to use neutral rather than alkaline solutions;

- reduction of the process temperature from 140 to $70-80^{\circ} \mathrm{C}$;

- increasing the anticorrosive properties of CCs using new passivating aqueous formulations or surface superhydrophobization.

The transition from traditional alkaline blackening of steel to oxidation in neutral nitrate solutions markedly improves the environmental safety and reduces the consumption of energy and reagents. However, the protective properties of these magnetite coatings (MCs) are inferior to those of the MCs prepared in alkaline baths. Therefore, we proposed to modify these films by adding small amounts of CIs to nitrate baths. Our studies showed [48] that in some cases, the thickness $(\delta)$ can be increased by heterocyclic CIs (Figure 8) without deteriorating the decorative properties of an $\mathrm{MC}$ and its adhesion to steel surface. Another way of improving an $\mathrm{MC}$ is to use complex-forming CIs, e.g., HEDP or its complexes [49]. The nature of the complexing cation of a CI plays an important role in $\mathrm{MC}$ modification. Cations of poorly soluble hydroxides are preferred, provided that they are not very large and do not distort the magnetite structure so much that its defectiveness would increase. The best results were obtained with the complex of $\mathrm{Al}^{3+}$ which has the smallest radius and the lowest solubility of hydroxide at elevated temperatures. This also agrees with the beneficial effect of small amounts of lithium nitrate and aluminum added to a solution containing $25 \mathrm{~g} / \mathrm{l}$ of $\mathrm{NH}_{4} \mathrm{NO}_{3}$, which makes it possible to reduce the oxidizing bath temperature to $70^{\circ} \mathrm{C}[50]$. 


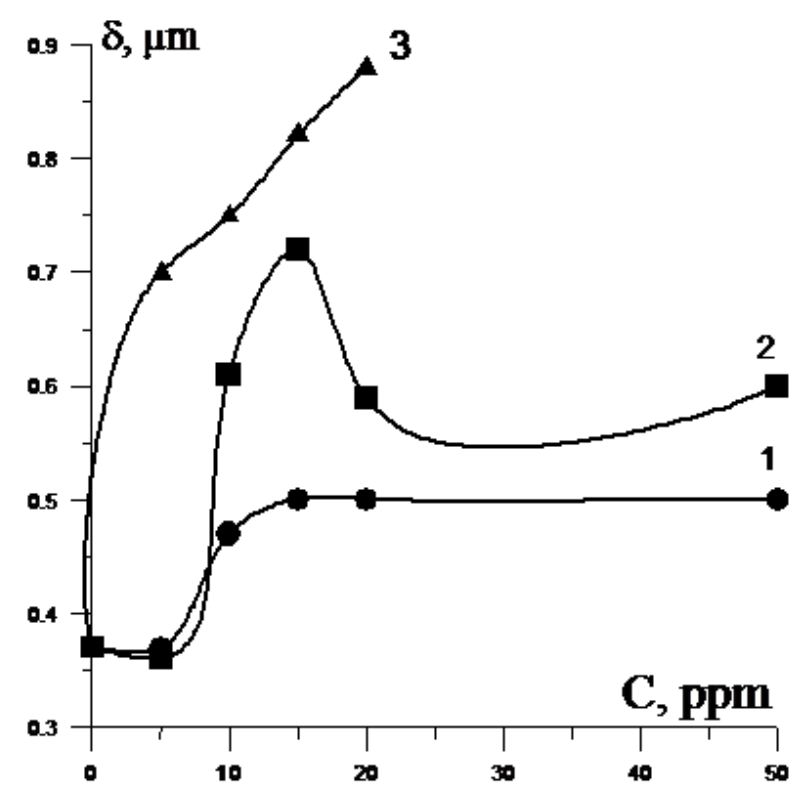

Figure 8. Effect of the concentration of additives in oxidizing solutions $\left(5 \mathrm{~g} / 1 \mathrm{NH}_{4} \mathrm{NO}_{3}, \mathrm{pH}\right.$ $7.5 ; 98^{\circ} \mathrm{C}, 40 \mathrm{~min}$ ) on the thickness of magnetite coating: 1 , BTA; 2 , benzimidazole; 3 , an Scontaining corrosion inhibitor.

The goal of further studies was to increase the corrosion resistance of the MC through its passivating treatment or to impart superhydrophobic properties to the surface. In the latter case, it is necessary to achieve multimodal roughness, i.e., create texture elements with dimensions related to different spatial scales on the oxidized surface [51]. A superhydrophobic coating was applied by depositing a wetting film of Aerosil dispersion nanoparticles with a specific surface area of $365 \mathrm{~m}^{2} / \mathrm{g}$ and a particle size of $20-200 \mathrm{~nm}$, coated with a hydrophobic agent. An ammonium nitrate solution containing small amounts of special additives, including aluminum nitrate (IFKhAN 9A), was used as the converting formulation, because it provided the highest contact angle (in degrees): $81.7 \pm 6.4$ without hydrophobization; $137.8 \pm 8.2$ after hydrophobization with a solution of fluorinated trialkoxysilanes (LFA 171) in decane; and $>160$ after superhydrophobization. The results of corrosion tests in a G-4 humidity chamber show that the time before the first corrosion damage appears on St3 steel with an MC pre-exposed to surface superhydrophobization is 2 times longer (50 days) than that for the samples of steel passivated in an aqueous solution of IFKhAN-39B (25 days).

Recently [52], we proposed a method of mild steel oxidizing successively in two baths. During oxidation in the first solution, a thin continuous MC is formed, and partial dissolution of the initial coating occurs in the second solution, whereby only the skeleton of the film consisting of the largest crystals remains. At a certain stage of the process, they take on the role of new crystallization centers, growth of which again gives a continuous but thicker film. The first solution contained an oxidizing composition based on $\mathrm{NH}_{4} \mathrm{NO}_{3}$ with $\mathrm{Zn}\left(\mathrm{NO}_{3}\right)_{2}$, which is an inhibitor of iron dissolution, as an additive. The second 
solution can contain $\mathrm{NH}_{4} \mathrm{NO}_{3}$, without or with an $\mathrm{MC}$ growth accelerator, e.g., ammonium persulfate.

Corrosion tests in a G-4 humidity chamber on steel St3 samples with MC formed in different oxidizing solutions and impregnated with passivating formulation IFKhAN-39 showed that the first corrosion damage of a sample with an MC formed in two baths was observed after 90 days, which is two times greater than for an $\mathrm{MC}$ obtained in one oxidation bath (Table 4).

Table 4. Tests of St3 steel oxidized in nitrate solutions with subsequent passivation in aqueous solutions of CIs or superhydrophobized with a layer of filler at $100 \%$ humidity and daily condensation of moisture on sample surface.

\begin{tabular}{|c|c|c|c|}
\hline Oxidizing solution & $\delta, \mu \mathbf{m}$ & Passivating treatment & $\begin{array}{c}\text { Time before } \\
\text { appearance of } \\
\text { corrosion damage, } \\
\text { days } \\
\end{array}$ \\
\hline $25 \mathrm{~g} / 1 \mathrm{NH}_{4} \mathrm{NO}_{3}\left(98^{\circ} \mathrm{C}\right)$ & 0.9 & Passivation by IFKhAN-39A & 30 \\
\hline \multirow[b]{2}{*}{ IFKhANOKS-9A $\left(70^{\circ} \mathrm{C}\right)$} & \multirow[b]{2}{*}{1.6} & Passivation by IFKhAN-39V & 43 \\
\hline & & $\begin{array}{c}\text { Superhydrophobization with a } \\
\text { layer of filler }\end{array}$ & 50 \\
\hline $\begin{array}{c}1^{\text {st }} \text { bath } \\
25 \mathrm{~g} / 1 \mathrm{NH}_{4} \mathrm{NO}_{3}+0,2 \mathrm{~g} / 1 \mathrm{Zn}\left(\mathrm{NO}_{3}\right)_{2}\end{array}$ & 1.1 & \multirow{2}{*}{ Passivation by IFKhAN-39U } & \multirow{2}{*}{90} \\
\hline $\begin{array}{c}2^{\text {nd }} \text { bath } \\
25 \mathrm{~g} / 1 \mathrm{NH}_{4} \mathrm{NO}_{3}\end{array}$ & 1.4 & & \\
\hline
\end{tabular}

Thus, improvement of the process of steel oxidation is primarily aimed at improving the ecological safety of the process and at reducing energy consumption. Moreover, it requires the development of more efficient methods of MC passivation, including its relatively new method consisting of MC superhydrophobization. Progress in this area creates good prospects for wider practical use of CCs on metals and alloys.

Corrosion inhibitors for paint coatings. I.L.Rosenfeld paid a lot of attention to the development of scientific bases for creation of such inhibitors [53]. Nowadays these CIs have changed significantly. Replacement of chromate-based corrosion inhibitors and pigments by non-toxic compounds and their encapsulation plays an important role in this approach. Analysis of the possibilities of encapsulation and their use in protective polymer coatings is discussed in many papers [54-63]; a detailed review of this issue requires a separate publication. In view of this, let us just briefly list the most obvious advantages of using CI in encapsulated form. These are:

- reducing the consumption of $\mathrm{CI}$ and its harmful effects on important properties of the coating (adhesion, drying time, etc.);

- elimination of CI deactivation by components of the coating; 
- applicability to various types of coatings, including water-based primers and $\mathrm{Zn}$-filled protective coatings;

- control of CI release: desorption control, $\mathrm{pH}$-control, ion-exchange control, release under mechanical rupture;

- significant expansion of the scope of potential CIs;

- possibility to create self-healing paints.

These benefits alone are sufficient to recognize that this approach to CI application forms a separate, quite promising scientific direction within the corrosion protection of metals. It does not always look economically attractive, but we do believe that application of encapsulated CIs will be estimated in such a way less frequently because the encapsulation techniques will undoubtedly be improved and will become cheaper. That is why this method of protecting metals, sometimes rightly called "active", will take a prominent place in practice in the near future.

\section{Conclusions}

The theory of action of corrosion inhibitors has been continuing to develop in the recent decades, and they are finding new areas of application in the practice of anti-corrosion protection. A new possibility for improving the anticorrosion protection of metals is opened by design and construction of bi- or even multi-layer nanocoatings from aqueous solutions or from vapor phase. High-temperature acid CIs, Migrating CIs, Volatile CIs and other new types of CIs deserve special attention, because they might help to solve complex problems that seemed intractable until recently.

\section{References}

1. N. P. Andreeva and Yu. I. Kuznetsov, Protection of Metals, 1987, 23, no. 4, 601; 1989, 25, no. 2, 214.

2. L. P. Hammett, Organic chemistry. Reaction rates, equilibria and mechanisms, McGraw-Hill Book Company, New York, 1970.

3. Yu. I. Kuznetsov, Yu. A. Fialkov and L. I. Popova, Protection of Metals, 1982, 18, no. $1,12$.

4. Yu. I. Kuznetsov, Organic Inhibitors of Corrosion of Metals, New York and London, Plenum Press. 1996.

5. Ya. G. Bober, Yu. I. Kuznetsov and N. P. Andreeva, Protection of Metals, 2008, 44, no. $1,84$.

6. Yu. I. Kuznetsov, N. P. Andreeva and Ya. G. Bober, Appl. Surf. Sci., 2010, no. 257, 1166.

7. A. I. Martin, F. Yubero, J. P. Espinos and S. Tougaard, Surf. Interf. Anal., 2004, 36, 788.

8. F. X. Perrin and J. Pagetti, Corros. Sci., 1998, 40, 1647.

9. Yu. I. Kuznetsov and L. P. Kazansky, Russ. Chem. Rev., 2008, 77, no. 3, 219.

10. J. C. Marconato, L. O. Bulhes and M. L. Temperini, Electrochim. Acta., 1998, 43, 771. 
11. B. Assouli, A. Shiri and H. Idrissi, Corrosion, 2004, 60, 399.

12. L. P. Kazansky, I. A. Selyaninov and Yu. I. Kuznetsov, Appl. Surf. Sci., 2012, no. 258, 6807.

13. Yu. I. Kuznetsov, M. O. Agafonkina, H. S. Shikhaliev, N. P. Andreeva and A. Yu. Potapov, Int. J. Corros. Scale Inhib., 2014, 3, no. 2, 137. doi: 10.17675/2305-6894-20143-2-137-148

14. Yu. I. Kuznetsov, M. O. Agafonkina, H. S. Shikhaliev, N. P. Andreeva and A. Yu. Potapov, Korroz.: Mater. Zashch., 2014, in press (in Russian).

15. Yu. I. Kuznetsov and L. P. Podgornova, Russ. J. Electrochem., 1984, 20, no. 7, 982.

16. Yu. I. Kuznetsov and L. P. Podgornova, Protection of Metals, 1993, 29, no. 3, 471.

17. K.B.Yatsimirsky, Zh. Neorg. Khim., 1957, 2, no. 10, 2346 (in Russian).

18. G.W. Poling, J. Electrochem. Soc., 1967, 114, 1209.

19. N. I. Podobaev and V. I. Kotov, Zh. Prikl. Khim., 1969, 69, 1569 (in Russian).

20. F. Zucchi, G. Trabanelli and G. Brunoro, Corros. Sci., 1994, 36, 1683.

21. A. Frignani, C. Monticelli, F. Zucchi and G. Trabanelli, Int. J. Corros. Scale Inhib., 2014, 3, no. 2, 105. doi: 10.17675/2305-6894-2014-3-2-105-119

22. Ya. G. Avdeev, Yu. I. Kuznetsov and A. K. Buriak, Corros. Sci., 2013, 69, 50.

23. F. D. Osterholtz, E. R. Pohl and J. Adhesion, Sci. Technol., 1992, 6, 127.

24. A. A. Chirkunov, A. M. Semiletov, Yu. I. Kuznetsov and N. P. Andreeva, Korroz. Mater. Zashch., 2013, no. 11, 27 (in Russian).

25. C. Hanch and A. Leo, Correlation analysis in chemistry and biology, New York, John Wiley \& Sons Ltd., 1981.

26. Yu. I. Kuznetsov, A. A. Chirkunov, N. P. Andreeva and A. S. Gorbachev, Corros. Sci., 2014 (in press).

27. Yu. I. Kuznetsov, N. P. Andreeva and M. O. Agafonkina, Russ. J. Electrochem., 2010, 46, no. 5, 560 .

28. Yu. I. Kuznetsov, N. P. Andreeva and M. O. Agafonkina, Protection of Metals and Physical Chemistry of Surfaces, 2010, 46, no. 5, 604.

29. Yu. I. Kuznetsov and N. P. Andreeva, Russ. J. Electrochem., 2005, 41, no. 6, 575; 2006, 42, no. 10, 1101.

30. Yu. I. Kuznetsov, M. O. Agafonkina and N. P. Andreeva, Korroz. Mater. Zashch., 2013, no. 2, 25 (in Russian).

31. Yu. I. Kuznetsov, A. A. Chirkunov and I. A. Filippov, Russ. J. Electrochem., 2013, 49, no. $12,1235$.

32. N. N. Andreev, Protection of Metals, 1998, 34, no. 2, 101.

33. Yu. I. Kuznetsov, N. N. Andreev, O. A. Goncharova and A. V. Agafonkin, Korroz. Mater. Zashch., 2009, no. 10, 29 (in Russian).

34. A. V. Agafonkin, Yu. I. Kuznetsov and N. P. Andreeva, Protection of Metals and Physical Chemistry of Surfaces, 2011, no. 7, 866.

35. N. N. Andreev, K. A. Ibatullin, Yu. I. Kuznetsov and S. V. Oleinik, Protection of Metals, 2000, 36, no. 3, 235. 
36. Yu. I. Kuznetsov and K. A. Ibatullin, Protection of Metals, 2002, 38, no. 5, 439.

37. Yu. I. Kuznetsov and R. K. Vagapov, Protection of Metals, 2000, 36, no. 5, 474.

38. Yu. I. Kuznetsov, L. V. Frolova and E. V. Tomina, Protection of Metals, 2007, 43, no. $2,149$.

39. Russian Federation Patent no. 2460828, published 16.06.2011 (in Russian).

40. R. V. Kashkovskiy, Yu. I. Kuznetsov and L. P. Kazansky, Corros. Sci., 2012, 64, 126.

41. R. V. Kashkovskiy, Yu. I. Kuznetsov, Int. J. Corros. Scale Inhib., 2012, 1, 117. doi: 10.17675/2305-6894-2012-1-2-117-129

42. B. Miksik, L. Gelner, D. Jegovic and L. Sipos, Proceedings of $8^{\text {th }}$ European Symp. on Corros. Inhibitors, 1995, Ferrara (Italy), Vol. 1, 569.

43. E. V.Starovoitova, Abstract of Candidate Dissertation (Chemistry), Moscow, IFKhE RAN, 2008 (in Russian).

44. N. N. Andreev, D. S. Bulgakov, I. A. Gedvillo and A. S. Zhmakina, Korroz. Mater. Zashch., 2014, no. 12, 24 (in Russian).

45. Russian Federation Patent no. 2413038, published 27.02.2011 (in Russian).

46. Ya. G. Avdeev and Yu. I. Kuznetsov, Russ. Chem. Rev., 2012, 81, no. 12, 1133.

47. Ya. G. Avdeev and A. Yu. Luchkin, Int. J. Corros. Scale Inhib., 2013, 2, 53. doi: 10.17675/2305-6894-2013-2-1-053-066

48. Yu. I. Kuznetsov, Green Inhibitors for Improving Conversion Coatings on Metals, in: Reviews on Corrosion Inhibitor Science and Technology, Vol. 3, Eds. A. Raman, P. Labine and D. V. S. Gupta, 2004, NACE International, Houston (USA), 7-1-13.

49. Yu. I. Kuznetsov, D. B. Vershok and T. I. Bardasheva, Protection of Metals, 1996, 32, no. $1,1$.

50. Yu. I. Kuznetsov, D. B. Vershok and D. S. Bulgakov, Korroz. Mater. Zashch., 2010, no. 3, 38 (in Russian).

51. D. A. Alpysbaeva, D. B. Vershok, A. M. Emelianenko, O. V. Batischev, Yu. I. Kuznetsov, L. B. Boynovich, Protection of Metals and Physical Chemistry of Surfaces, 2014, 50, no. 7, 898.

52. D. V. Vershok, D. N. Orlov, Yu. A. Ionov, O. V. Sorokina and Yu. I. Kuznetsov, Korroz. Mater. Zashch., 2014, no. 4, 39 (in Russian).

53. I. L. Rozenfeld and F. I. Rubinshtein, Antikorrozionnye gruntovki i ingibirovannye lakokrasochnye pokrytiya (Anticorrosion Primers and Inhibited Paint Coatings), 1980, Moscow, Khimiya (in Russian).

54. N. N. Voevodin, V. N. Balbyshev, M. Khobaib and M. S. Donley, Prog. Org. Coat., 2003, 47, 416.

55. A. Kumar, L. D. Stephenson and J. N. Murray, Prog. Org. Coat., 2006, 55, 244.

56. W. Li and L. M. Calle, Corrosion NACE, 2007, Paper 07228, Nashville, TN, March 2007.

57. M. I. Zheludkevich, D. G. Shchukin, K. A. Yasakau, H. Möhwald and M. G. S. Ferreira, Chemistry of Materials, 2007, 19, 402.

58. C. Suryanarayana, K. C. Rao and D. Kumar, Prog. Org. Coat., 2008, 63, 72. 
59. D. G. Shchukin, S. V. Lamaka, K. A. Yasakau, M. I. Zheludkevich, H. Möhwald and M. G. S. Ferreira, J. Phys. Chem. C, 2008, 112, 959.

60. D. V. Andreeva, D. Fix, H. Möhwald and D. G. Shchukin, Adv. Mater., 2008, 20, 2789.

61. M. I. Zheludkevich， S. K. Poznyak， L. M. Rodrigues， D. Raps，T. Hack， L. F. Dick, T. Nunes and M. G. S. Ferreira, Corros. Sci., 2011, 52, 602.

62. V. A. Golovin, Protection of Metals and Physical Chemistry of Surfaces, 2011, 47, no. 7,830 .

63. M. I. Zheludkevich, J. Tedim and M. G. S. Ferreira, Electrochim. Acta, 2012, 82, 314. 